\title{
Social cognition and its relationship to functional outcomes in patients with sustained acquired brain injury
}

This article was published in the following Dove Press journal:

Neuropsychiatric Disease and Treatment

3 November 2014

Number of times this article has been viewed

\author{
Shiho Ubukata ${ }^{1,2}$ \\ Rumi Tanemura ${ }^{2}$ \\ Miho Yoshizumi' \\ Genichi Sugihara' \\ Toshiya Murai' \\ Keita Ueda' \\ 'Department of Psychiatry, Graduate \\ School of Medicine, Kyoto University, \\ Kyoto, ${ }^{2}$ Department of Rehabilitation \\ Science, Graduate School of Health \\ Sciences, Kobe University, Kobe, Japan
}

Correspondence: Shiho Ubukata Department of Psychiatry, Graduate School of Medicine, Kyoto University, 54 Kawaharacho, Kyoto 606-8507, Japan Tel +817575 I 4947

Fax +8I7 575I 3382

Email ubukata@kuhp.kyoto-u.ac.jp

\begin{abstract}
Deficits in social cognition are common after traumatic brain injury (TBI). However, little is known about how such deficits affect functional outcomes. The purpose of this study was to investigate the relationship between social cognition and functional outcomes in patients with TBI. We studied this relationship in 20 patients with TBI over the course of 1 year postinjury. Patients completed neurocognitive assessments and social cognition tasks. The social cognition tasks included an emotion-perception task and three theory of mind tasks: the Faux Pas test, Reading the Mind in the Eyes (Eyes) test, and the Moving-Shapes paradigm. The Craig Handicap Assessment and Reporting Technique was used to assess functional outcomes. Compared with our database of normal subjects, patients showed impairments in all social cognition tasks. Multiple regression analysis revealed that theory of mind ability as measured by the Eyes test was the best predictor of the cognitive aspects of functional outcomes. The findings of this pilot study suggest that the degree to which a patient can predict what others are thinking is an important measure that can estimate functional outcomes over 1 year following TBI.
\end{abstract}

Keywords: Eyes test, social emotion perception, social function, social participation, theory of mind

\section{Introduction}

Impairments in several cognitive domains are common after traumatic brain injury (TBI),${ }^{1-4}$ and include neurocognitive domains such as attention, cognitive processing speed, memory, and executive function. ${ }^{5}$ These impairments can be important predictors of social function or functional outcomes in patients with TBI. ${ }^{6-9}$

Along with neurocognition, patients with TBI show impairments in social cognition. Social cognition is a comprehensive term that includes several abilities, from the simple perception of facial emotions to the more complex ability of inferring others' mental state from subtle cues. ${ }^{10}$ The perception of basic facial emotions has been frequently investigated in individuals with TBI, with impairments in this ability being demonstrated repeatedly. ${ }^{11-16}$ Another important element of social cognition is theory of mind (ToM), which allows one to infer the mental states of others (including their intentions, desires, thoughts, beliefs, dreams, and pretenses). ${ }^{17,18}$

The Faux Pas test is a frequently used verbal ToM task, while the Reading the Mind in the Eyes (Eyes) test is a frequently used nonverbal ToM task. Reports indicate that patients with TBI are impaired in both of these tasks. ${ }^{13,14,19-22}$ To assess automatic ToM, which is thought to involve simulating real-world social interactions, the Moving-Shapes paradigm is used. ${ }^{23}$ This requires the participant to interpret intentional movements. ${ }^{24}$ Although social cognition is also thought to be an important predictor 
of how TBI patients function in the real world, ${ }^{25}$ few studies have investigated the relationship between social cognition and social function.

The purpose of this pilot study was to determine whether social cognition can predict functional outcomes in patients with TBI. We evaluated major aspects of social cognition in patients with TBI, specifically basic emotion perception and multiple ToM components. We also conducted within-subject analyses to investigate the relationship of task-determined social cognition with real-life social functioning. We hypothesized that after accounting for the impaired neurocognition, impairments in social cognition would be good predictors of poor social ability in patients with TBI. To the best of our knowledge, no study has investigated multiple aspects of social cognition in terms of their relationship to social functioning in patients with TBI. Specifying which domains can predict disturbances in social functioning is crucial for developing effective training programs and useful interventions in patients with TBI.

\section{Materials and methods}

\section{Participants}

Participants were recruited from outpatient department of the neuropsychology clinic at the Department of Psychiatry, Kyoto University Hospital, and in the vicinity of the hospital between 2009 and 2011. The inclusion criteria for patients were as follows: an injury sustained through significant trauma; loss of consciousness at the time of injury; brain magnetic resonance imaging (MRI) or computed tomography (CT) scan showing a specific lesion or diffuse axonal injury (DAI) lesion; over 18 years of age; and at least 1 year postinjury. We focused on patients who had sustained injuries more than 1 year before the study because impairments in social function typically become problematic at this stage, when the major concern of patients and caregivers is readaptation in school, jobs, or the community. Furthermore, deficits in social cognition persist post-injury. ${ }^{26,27}$ The exclusion criteria were: visual or visuoperceptual deficits, previous history of TBI, history of drug abuse, or history of neurologic or psychiatric disorders before TBI onset.

Clinical data at onset were obtained from the medical records of the emergency unit. Diagnoses were made based on clinical information and neuroimaging findings. Neuropsychiatrists (UK, TM) specialized in the neuropsychiatric aspects of TBI confirmed the information concerning the clinical history and residual symptoms related to the inclusion and exclusion criteria mentioned above in semistructured interviews with patients and their families, and chart reviews.
The neuropsychiatrists also reviewed CT scans or magnetic resonance images. Definitions of DAI and frontal injuries were as follows: CT or MRI scans showing possible diffuse pathology were defined as DAI, and patients with larger lesions $(>2 \mathrm{~mm})$ within the frontal lobes (detected by CT or MRI) were defined as having frontal injuries.

Twenty patients with TBI (14 male) of mean ( \pm standard

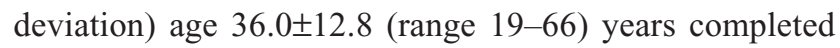
the study. Table 1 shows the patients' demographic and clinical information. All patients were native Japanese. Education ranged from 9 to 19 years of schooling (mean $12.9 \pm 2.8$ years). The time since TBI onset ranged from 19 to 276 (mean 108.4 \pm 79.3 ) months. We confirmed from the medical records that all the patients experienced loss of consciousness. Because information on the duration of lost consciousness was not available in some patients, we used the range of post-traumatic amnesia as an index of injury severity. The mean duration of post-traumatic amnesia was 63 days (range 5 hours to 180 days), and was determined based on detailed interviews with patients and their family members. First, we obtained a chronological list of events during hospitalization from family members, and then determined whether patients themselves could remember each event. Seventeen of the 20 participants had severe TBI according the criteria of Arlinghaus et $\mathrm{al}^{28}$ and this number rose to 19 when using the criteria of Russell and Smith. ${ }^{29}$ All patients were diagnosed as currently having F04 and/ or F06 psychiatric disorder(s) based on the 10th revision of the International Statistical Classification of Diseases and Related Health Problems. ${ }^{30}$ Regarding medication at the time of testing, eight were taking anticonvulsants, three were taking amantadine and bromocriptine for symptoms of apathy, two were taking selective serotonin reuptake inhibitors for emotional lability, and two were taking lithium for manic symptoms. Eight patients were not taking medication. Nine patients had previously received rehabilitation treatment for executive function or memory deficits. None had received specific social skills training.

This study was approved by the committee on medical ethics at Kyoto University and carried out in accordance with The Code of Ethics of the World Medical Association. Written informed consent was obtained after participants received a complete description of the study.

\section{Neurocognitive assessments}

All participants completed a standardized comprehensive neuropsychological test battery. General intelligence was assessed by the Wechsler Adult Intelligence Scale-III/Revised 
Table I Demographic and clinical characteristics of participants

\begin{tabular}{|c|c|c|c|c|c|c|c|}
\hline $\begin{array}{l}\text { Participant } \\
\text { number }\end{array}$ & $\begin{array}{l}\text { Age } \\
\text { (years) }\end{array}$ & Sex & $\begin{array}{l}\text { Education } \\
\text { (years) }\end{array}$ & $\begin{array}{l}\text { Cause of } \\
\text { injury }\end{array}$ & $\begin{array}{l}\text { PTA } \\
\text { (days) }\end{array}$ & $\begin{array}{l}\text { Time post- } \\
\text { injury (months) }\end{array}$ & Injury type (CT or MRI scan) \\
\hline 1 & 22 & M & 9 & Traffic accident & 90 & 74 & DAl \\
\hline 2 & 32 & M & 12 & Fall & 180 & 62 & DAI \\
\hline 3 & 42 & M & 12 & Traffic accident & 40 & 276 & DAI \\
\hline 4 & 19 & M & 12 & Traffic accident & 60 & 41 & DAI \\
\hline 5 & 33 & $\mathrm{~F}$ & 9 & Traffic accident & 90 & 180 & DAl \\
\hline 6 & 32 & M & 12 & Traffic accident & 40 & 192 & Bilateral orbito-medial frontal \\
\hline 7 & 33 & M & 12 & Traffic accident & 150 & 185 & DAl \\
\hline 8 & 24 & M & 12 & Traffic accident & 180 & 62 & DAI \\
\hline 9 & 29 & M & 12 & Falling object & 30 & 180 & DAI \\
\hline 10 & 66 & M & 9 & Fall & 21 & 75 & DAl \\
\hline 11 & 46 & $\mathrm{~F}$ & 14 & Traffic accident & 0.25 & 41 & Right prefrontal-temporal pole \\
\hline 12 & 43 & $\mathrm{~F}$ & 16 & Traffic accident & 7 & 60 & Bilateral orbitofrontal-frontal pole \\
\hline 13 & 42 & $\mathrm{~F}$ & 15 & Traffic accident & 3 & 232 & DAI \\
\hline 14 & 44 & M & 16 & Traffic accident & 180 & 38 & Bilateral orbitofrontal left temporal pole \\
\hline 15 & 46 & M & 16 & Traffic accident & 40 & 195 & DAI \\
\hline 16 & 64 & $\mathrm{~F}$ & 15 & Traffic accident & 7 & 24 & DAI \\
\hline 17 & 36 & M & 16 & Traffic accident & 30 & 19 & Left frontal pole \\
\hline 18 & 28 & M & 13 & Traffic accident & 60 & 228 & Right ventral prefrontal \\
\hline 19 & 23 & M & 9 & Traffic accident & 60 & 36 & DAI \\
\hline 20 & 28 & $\mathrm{~F}$ & 12 & Traffic accident & 5 & 139 & $\mathrm{DAl}$ \\
\hline
\end{tabular}

Abbreviations: PTA, post-traumatic amnesia; M, male; F, female; DAl, diffuse axonal injury; CT, computed tomography; MRI, magnetic resonance imaging.

(WAIS-III/WAIS-R), memory function by the Wechsler Memory Scale-Revised, and executive function by the Behavioural Assessment of the Dysexecutive Syndrome (BADS) ${ }^{31}$ As this study was conducted during the period in which the Japanese translation of the WAIS-III was introduced, we used both the WAIS-III and the WAIS-R. We administered all the subtests of these assessments.

\section{Social cognition tasks}

Participants completed four different tests involving one emotion perception task and three ToM tasks. We used assessments of emotion perception, verbal ToM, nonverbal ToM, and automatic ToM. Many studies have used the first three of these tasks when testing TBI patients. We adopted the assessment tools that have been most frequently applied in the literature. For assessing automatic ToM, we used the Moving-Shapes paradigm, which has been used frequently to evaluate psychiatric conditions such as schizophrenia, autism, and depression. To minimize fatigue, assessment time did not exceed 3 hours per day, and was completed over the course of $4-5$ days within a 3-week period.

\section{Measure of emotion perception}

Participants were presented with a sequence of 48 photographs from the Matsumoto and Ekman ${ }^{32,33}$ set of faces depicting anger, happiness, fear, disgust, sadness, and surprise.
For each face, the participant was asked to identify which of these six labels best described the face. The participant received one point for each correct answer.

\section{Theory of mind measurement Faux Pas test}

Participants were presented with 20 stories taken from the adult version of the Faux Pas test, ${ }^{34}$ comprising ten stories containing a faux pas and ten control stories. After reading the story, we asked whether anyone in the story had said something they should not have been said or that was awkward (faux pas-related questions). If the participant correctly answered "yes" for a faux pas story, we then asked five more questions to make sure that their answer reflected an understanding of the faux pas (ie, knowing what was offensive). Finally, as a control for story comprehension, the participant was asked a question about some important detail of the story (memory questions). The participant received one point for each correct answer.

\section{Eyes test}

Each participant was presented with a series of 36 photographs of eyes and asked to indicate which of four simultaneously presented words best described the mental state of the photographed person ${ }^{35}$ (Figure 1). The participant was asked to choose the word they considered the most suitable, and received one point for each correct answer. 


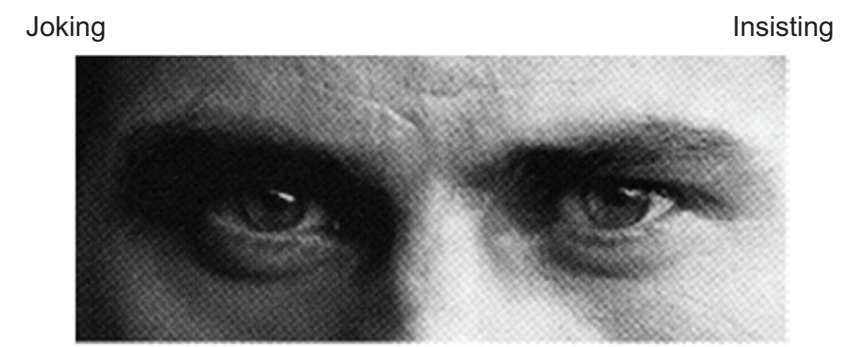

Amused

Relaxed

Figure I Example of an item in the Eyes test.

\section{Moving-Shapes paradigm}

We presented participants with the Moving-Shapes paradigm ${ }^{23}$ using the original 12 silent animated movies (see http://sites. google.com/site/utafrith/research for examples). A big red triangle and a small blue triangle were presented, both of which moved on a framed white screen. Three types of animations were displayed: random-movement video sequences, in which the triangles purposelessly moved around (eg, bouncing off the walls); goal-directed sequences, in which one triangle acted and the other one reacted (eg, fighting), but there was no indication of reading the other's mind; and ToM sequences in which the triangles interacted as if they read each other's minds (eg, seducing). Each video lasted 40 seconds. Participants were asked what they thought the triangles were doing, and answers were evaluated using the scoring criteria provided by Abell et al. ${ }^{23}$ Experienced raters graded answers on intentionality (degree of mental state attribution, amount of ToM-related language use; $0-5$ points), appropriateness of the answers (degree of correctness; $0-4$ points), and certainty and length of answers ( $0-4$ points). Of these four aspects, here we consider only the intentionality score of the ToM sequences.

\section{Functional outcomes}

The Japanese version of the Revised Craig Handicap Assessment and Reporting Technique (R-CHART) ${ }^{36,37}$ was used to assess patients' overall function levels. The R-CHART is a self-reported scale completed by patients themselves, was designed to measure how much people suffering from TBI participate in the community, and is based on the World Health Organization model of disabilities. Thirty-two questions are divided into six categories: physical independence, cognitive independence, mobility, occupation, social integration, and economic self-sufficiency. The R-CHART items are intended to assess observable behaviors and criteria for disabilities, rather than perceptions. ${ }^{38}$ Subscale scores range from 0 to 100 , with the maximum score corresponding to the expected score of a person without a disability. Thus, a high score on this scale indicates good social participation.

\section{Analyses}

We describe the results of the three ToM tasks and the emotion-perception task with reference to our database of scores for these tests from normal individuals, which were obtained using the same methods described here. To investigate the relationships between functional outcomes and each cognitive domain, statistical analyses were performed using Statistical Package for the Social Sciences version 21.0 software (SPSS Inc., Chicago, IL, USA). First, we calculated Spearman's rank order coefficients to investigate simple correlations among scores for the various cognitive domains and each subscale score of the R-CHART. Cognitive domains included the full intelligence quotient (measured by the WAIS), general memory (measured by the Wechsler Memory Scale-Revised), general score of executive function (measured by the BADS), and social cognition (assessed with emotion perception, the Faux Pas test, the Eyes test, and the Moving-Shapes paradigm). When significant correlations between social cognition measures and R-CHART subscale measures were found, multiple regression analyses were applied. We set the R-CHART measures as dependent variables and the social cognition measures and neuropsychological assessments as independent variables in the multiple regression analysis using the forced entry method.

\section{Results \\ Neurocognition, social cognition, and functional outcomes}

Table 2 shows the means, standard deviations, and standard scores for intelligence quotient, memory, and executive function. The scores were lower compared with standard scores

Table 2 Neurocognitive assessment scores

\begin{tabular}{llllll}
\hline \multirow{2}{*}{ Test } & \multicolumn{2}{c}{ Raw score } & & \multicolumn{2}{c}{ Standard score } \\
\cline { 2 - 2 } & Mean & SD & & Mean & SD \\
\hline WAIS-R/III & 90.2 & 16.1 & & 100 & 15 \\
VIQ & 80.1 & 12.3 & 100 & 15 \\
PIQ & 85.9 & 14.2 & & 100 & 15 \\
FIQ & & & & \\
WMS-R & 78.1 & 17.7 & & 100 & 15 \\
$\quad$ Verbal memory & 82.9 & 26.0 & 100 & 15 \\
Visual memory & 79.1 & 22.7 & 100 & 15 \\
General memory & 94.0 & 16.4 & 100 & 15 \\
$\quad$ Attention & 71.0 & 23.4 & 100 & 15 \\
$\quad$ Delay memory & & & & 15 \\
BADS & 85.6 & 19.7 & 100 & \\
$\quad$ General score & &
\end{tabular}

Abbreviations: WAIS-R/III, Wechsler Adult Intelligence Scale-III/Revised; VIQ, Verbal Intelligence Quotient; PIQ, Performance Intelligence Quotient; FIQ, Full Intelligence Quotient; WMS-R, Wechsler Memory Scale-Revised; BADS, Behavioural Assessment of the Dysexecutive Syndrome; SD, standard deviation. 
Table 3 Performance on social cognition tasks: patients with TBI and healthy participants in our database

\begin{tabular}{|c|c|c|c|c|c|c|c|}
\hline & \multicolumn{2}{|c|}{$\begin{array}{l}\text { TBI patients } \\
(n=20)\end{array}$} & \multicolumn{2}{|c|}{$\begin{array}{l}\text { Healthy } \\
\text { subjects }\end{array}$} & \multicolumn{2}{|c|}{$\begin{array}{l}\text { Demographics of healthy } \\
\text { participants }\end{array}$} & \multirow[t]{2}{*}{ Reference } \\
\hline & Mean & SD & Mean & SD & $\begin{array}{l}\text { Age, years } \\
(\text { mean } \pm \text { SD })\end{array}$ & $\begin{array}{l}\text { Sex (male } \\
\text { to female) }\end{array}$ & \\
\hline Emotion perception & 60.0 & 11.9 & 90.2 & 4.7 & $32.4 \pm 8.1$ & $4: 6$ & Kubota et a ${ }^{39}$ \\
\hline Faux Pas test & 67.3 & 26.8 & 90.5 & 8.2 & $34.9 \pm 8.1$ & $14: 14$ & $\begin{array}{l}\text { Oshita et al, } \\
\text { unpublished data, } 2009\end{array}$ \\
\hline Eyes test & 50.8 & 9.4 & 67.6 & 5.9 & $35.0 \pm 7.1$ & $10: 10$ & Hirao et $\mathrm{a}^{40}$ \\
\hline Moving-Shapes test & 62.5 & 13.5 & 76.0 & 24.0 & $39.1 \pm 10.8$ & $16: 14$ & Koelkebeck et $\mathrm{al}^{4 \text { I }}$ \\
\hline
\end{tabular}

Note: Scores were converted into percentages to allow comparison across tasks.

Abbreviations: $\mathrm{TBI}$, traumatic brain injury; SD, standard deviation.

on the relevant tests (intelligence, WAIS-R/III; memory function, Wechsler Memory Scale-Revised; executive function, BADS). Table 3 summarizes patients' scores for each social cognition task along with those of healthy participants taken from the normal database. ${ }^{39-41}$ These scores were converted into percentages to allow a visual comparison with scores in our normal control database. The mean, standard deviation, and the maximum possible score for each subscale of the R-CHART are shown in Table 4.

\section{Correlations between social cognition and functional outcomes}

Correlations between social cognition and functional outcomes are shown in Table 5. Eyes test scores positively correlated with the R-CHART subscale of cognitive independence ( $r=0.603, P=0.005)$. This correlation was still significant even after controlling for demographic variables such as age, sex, and education using partial correlation analyses $(r=0.692, P=0.002)$. As we included patients with a wide range of severity levels, we reran a correlation analysis including only patients with severe TBI $(\mathrm{n}=17)$. The result was still significant $(r=0.568, P=0.017)$. No significant correlations were found between other social cognition scores and functional outcomes, or between neurocognitive assessments and functional outcomes. Results of a multiple

Table 4 Social participation scores of TBI patients according to R-CHART

\begin{tabular}{llll}
\hline Domain & Mean & SD & Maximum score \\
\hline Physical independence & 99.3 & 1.7 & 100 \\
Cognitive independence & 66.3 & 21.0 & 100 \\
Mobility & 77.6 & 21.4 & 100 \\
Occupation & 37.8 & 35.4 & 100 \\
Social integration & 51.0 & 27.7 & 100 \\
Economic self-sufficiency & 40.0 & 34.8 & 100 \\
\hline
\end{tabular}

Note: Range is from 0 (poorest social participation) to 100 (best social participation). Abbreviations: SD, standard deviation; TBI, traumatic brain injury; R-CHART, Revised Craig Handicap Assessment and Reporting Technique. regression analysis confirmed that the social cognition effect was independent from the neurocognitive effect (Table 6; $\left.R^{2}=0.31, f^{2}=0.45, F[4.15]=3.13, P=0.04\right)$. R-CHART $\operatorname{cog}$ nitive independence was the only subscale significantly predicted by the Eyes test $(\beta=0.637, P=0.005)$.

\section{Discussion}

The aim of this study was to explore the relationship between multiple aspects of social cognition and social function in patients who had suffered TBI at least 1 year before testing. Assessments suggested that patients were impaired in both neurocognitive and social cognition. The subjects also had impairments in social participation, although they were physically well. We found a significant correlation between nonverbal aspects of theory of mind and cognitive aspects of functional outcomes in patients with TBI. This correlation was not explained by the effects of impaired neurocognition.

To our knowledge, this is the first demonstration of a significant relationship between social cognition and functional outcomes in patients with TBI. In this study, one aspect of social cognition, ie, theory of mind, correlated with functional outcomes independently of neurocognition. Several studies have examined relationships between social cognition and behavioral change (eg, inappropriate social behavior) in TBI patients. While no study has found any significant relationship between these factors, ${ }^{19}$ this may be attributable to the heterogeneity of the samples, disparate sample sizes, and the different measurements employed in these studies. Future studies need to have larger sample sizes and clearly specify which type of TBI is related to the impairments in question (eg, focal injury versus diffuse axonal injury).

Among the many elements of social cognition and functional outcomes, we found a positive correlation between scores on the Eyes test and those on the R-CHART cognitiveindependence subscale. A low score on this subscale means that the patient has difficulty communicating with others and 
Table 5 Correlations between neurocognition, social cognition, and each subscale of functional outcome

\begin{tabular}{|c|c|c|c|c|c|c|}
\hline & \multicolumn{6}{|l|}{ R-CHART } \\
\hline & $\begin{array}{l}\text { Physical } \\
\text { independence }\end{array}$ & $\begin{array}{l}\text { Cognitive } \\
\text { independence }\end{array}$ & Mobility & Occupation & $\begin{array}{l}\text { Social } \\
\text { integration }\end{array}$ & $\begin{array}{l}\text { Economic } \\
\text { self-sufficiency }\end{array}$ \\
\hline \multicolumn{7}{|l|}{ Neurocognition } \\
\hline FIQ (WAIS) & -0.131 & 0.273 & 0.017 & 0.055 & 0.338 & 0.173 \\
\hline General memory (WMS-R) & -0.224 & 0.098 & -0.142 & 0.214 & 0.265 & 0.068 \\
\hline General score (BADS) & -0.391 & 0.198 & 0.227 & -0.110 & 0.212 & -0.227 \\
\hline \multicolumn{7}{|l|}{ Social cognition } \\
\hline Emotion perception & -0.001 & 0.340 & -0.177 & -0.059 & 0.267 & 0.322 \\
\hline Faux Pas test & -0.428 & -0.207 & -0.215 & 0.064 & -0.138 & 0.003 \\
\hline Eyes test & 0.156 & $0.603 * *$ & 0.308 & 0.329 & 0.100 & 0.402 \\
\hline Moving-Shapes test & -0.165 & -0.003 & -0.221 & -0.138 & 0.297 & 0.306 \\
\hline
\end{tabular}

Note: ${ }^{* *} p<0.01$, Spearman rank correlations.

Abbreviations: BADS, Behavioural Assessment of the Dysexecutive Syndrome; FIQ, Full Intelligence Quotient; R-CHART, Revised Craig Handicap Assessment and Reporting Technique; WMS-R, Wechsler Memory Score-Revised; WAIS, Wechsler Adult Intelligence Scale.

needs outside help in daily life..$^{42}$ One possible interpretation of this specific correlation is as follows: the four social cognition tasks employed here all capture different aspects of social cognition. The Faux Pas test and the Moving-Shapes test require the ability to interpret relationships among others or their intentions. In these tests, participants have to judge the situations from third person perspectives. In contrast, the emotion perception task and the Eyes test ask patients to judge the feelings represented in the target stimuli. Thus, these tasks simulate real-world situations in which participants themselves would be involved in social and emotional interactions. Furthermore, the Eyes test measures the ability of social emotion perception rather than that of basic emotion perception. Therefore, the Eyes test may be appropriate for measuring the ability of complex social/emotional perception.

On the other hand, the cognitive-independence subscale is a part of a self-evaluation questionnaire that requires patients to evaluate their own cognitive abilities. The other R-CHART subscales (ie, the mobility, occupation, social integration, and economic self-sufficiency subscales) are affected not only by patients' ability, but are also affected by environmental factors such as family support and social systems.

Table 6 Results of multiple regression analysis on R-CHART

\begin{tabular}{llll}
\hline $\begin{array}{l}\text { Dependent } \\
\text { variable }\end{array}$ & $\begin{array}{l}\text { Independent } \\
\text { variable }\end{array}$ & $\boldsymbol{R}^{2}$ & $\beta$ \\
\hline R-CHART & Eyes test & $0.310^{*}$ & $0.637^{* *}$ \\
Cognitive & FIQ & & -0.014 \\
independence & General memory & -0.021 \\
& Executive function & & -0.171 \\
\hline
\end{tabular}

Notes: Standardized regression coefficient; $* P<0.05$, $* * P<0.01$.

Abbreviations: R-CHART, Revised Craig Handicap Assessment and Reporting Technique; FIQ, Full Intelligence Quotient.
Thus, the cognitive-independence subscale may be sensitive to impaired social function per se in TBI. ${ }^{43}$ Taken together, these features of the Eyes test and the cognitive-independence subscale can be attributable to their specific relationship. The finding that other aspects of social cognition did not correlate with the other R-CHART subscales may be related to the nature of each task and subscale described above.

Although we did not apply exclusion or inclusion criteria regarding the type of injury, most patients in our sample had DAI or frontal injuries. In contrast with patients with other types of injury (eg, to the occipital region), patients with DAI or frontal injuries commonly show impairments in attention, memory, and executive function. ${ }^{44,45}$ Similarly, patients with frontal injuries often show more impaired social cognition when compared with those with injuries in other brain regions. ${ }^{46}$ Although the cause of social cognition deficits in patients with DAI is as yet undetermined, the nature of the diffuse injury suggests damage in brain regions such as the medial prefrontal cortex, superior temporal gyrus, amygdala, and cingulate cortex, which are critical in social cognition..$^{47,48}$ Thus, our study population may have more severe impairments in social cognition compared with patients suffering other types of TBI.

In addition to cognitive impairments, deficits in awareness have often been observed in patients with TBI. They may not recognize changes in themselves or their abilities following brain injury. ${ }^{49} \mathrm{We}$ did not evaluate self-awareness, and if deficits in awareness existed, they might have affected the self-reported functional outcomes. Thus, caution is needed in interpretation of our findings.

This study has several limitations. First, the small sample size is a major limitation. Second, we found a significant correlation between only one aspect of social cognition and one type of functional outcome. Without correcting for multiple comparisons, we cannot rule out the possibility that this result 
is a false positive. Thus, this study should be regarded as preliminary and the results should be re-examined in a larger number of participants. Third, because we focused on just a few particular social cognitive domains, we cannot generalize these results for all types of social cognition. Fourth, patients were under medication due to their neurological or psychiatric symptoms, and this may have affected the results. Fifth, we did not recruit age-matched and sex-matched control participants. Thus, we could not conduct statistical analyses showing that our patients exhibited significant impairments in social cognition. Finally, due to the characteristics of our sample, investigating the relationship between lesion location and social cognition or social functioning is difficult. Future study is necessary to investigate whether neurocognition, social cognition, functional outcomes, or correlations between these factors differ depending on lesion location.

In conclusion, we found a significant correlation between social cognition and functional outcome in patients suffering from a TBI that occurred over a year before testing. Our findings indicate that performance in social cognition tasks may be a good predictor of functional outcomes of patients with TBI. Supplementing routine neurocognitive assessment with social cognitive assessments will likely be informative. Furthermore, identifying this predictor of functional outcomes should hasten the development of training programs that focus on social cognition in patients with TBI.

\section{Acknowledgments}

We thank Uta and Chris Frith and their staff members for kindly providing the Moving-Shapes paradigm and rating descriptions. We also sincerely thank Katja Koelkebeck and Akira Oshita for their contribution to the data analysis. This work was supported by a Grant-in-Aid for Scientific Research in Innovative Areas (23118004) from the Ministry of Education, Culture, Sports, Science, and Technology of Japan, a Grant-in-Aid for Young Scientists B (23791328) and C (26461766) from the Japan Society for the Promotion of Science, and a research grant from the General Insurance Association of Japan.

\section{Disclosure}

The authors report no conflicts of interest in this work.

\section{References}

1. Levin H. Cognitive function outcomes after traumatic brain injury. Curr Opin Neurol. 1998;11(6):643-646.

2. Hellawell DJ, Taylor R, Pentland B. Cognitive and psychosocial outcome following moderate or severe traumatic brain injury. Brain Inj. 1999; 13(7):489-504.
3. Schretlen DJ, Shapiro AM. A quantitative review of the effects of traumatic brain injury on cognitive functioning. Int Rev Psychiatry. 2003;15(4):341-349.

4. Benedictus MR, Spikman JM, van der Naalt J. Cognitive and behavioral impairment in traumatic brain injury related to outcome and return to work. Arch Phys Med Rehabil. 2010;91(9):1436-1441.

5. Spikman JM, Timmerman ME, Milders MV, Veenstra WS, van der Naalt J. Social cognition impairments in relation to general cognitive deficits, injury severity, and prefrontal lesions in traumatic brain injury patients. J Neurotrauma. 2012;29(1):101-111.

6. Hanks RA, Rapport LJ, Millis SR, Deshpande SA. Measures of executive functioning as predictors of functional ability and social integration in a rehabilitation sample. Arch Phys Med Rehabil. 1999;80(9): 1030-1037.

7. Wood RL, Rutterford NA. Long-term effect of head trauma on intellectual abilities: a 16-year outcome study. J Neurol Neurosurg Psychiatry. 2006;77(10):1180-1184.

8. Spitz G, Ponsford JL, Rudzki D, Maller JJ. Association between cognitive performance and functional outcome following traumatic brain injury: a longitudinal multilevel examination. Neuropsychology. 2012; 26(5):604-612.

9. Manly T, Murphy FC. Rehabilitation of executive function and social cognition impairments after brain injury. Curr Opin Neurol. 2012;25(6): 656-661.

10. Adolphs R. Cognitive neuroscience of human social behaviour. Nat Rev Neurosci. 2003;4(3):165-178.

11. Hopkins MJ, Dywan J, Segalowitz SJ. Altered electrodermal response to facial expression after closed head injury. Brain Inj. 2002;16(3): 245-257.

12. McDonald S, Saunders JC. Differential impairment in recognition of emotion across different media in people with severe traumatic brain injury. J Int Neuropsychol Soc. 2005;11(4):392-399.

13. Henry JD, Phillips LH, Crawford JR, Ietswaart M, Summers F. Theory of mind following traumatic brain injury: the role of emotion recognition and executive dysfunction. Neuropsychologia. 2006;44(10): $1623-1628$.

14. Milders M, Ietswaart M, Crawford JR, Currie D. Social behavior following traumatic brain injury and its association with emotion recognition, understanding of intentions, and cognitive flexibility. J Int Neuropsychol Soc. 2008;14(2):318-326.

15. Callahan BL, Ueda K, Sakata D, Plamondon A, Murai T. Liberal bias mediates emotion recognition deficits in frontal traumatic brain injury. Brain Cogn. 2011;77(3):412-428.

16. Green RE, Turner GR, Thompson WF. Deficits in facial emotion perception in adults with recent traumatic brain injury. Neuropsychologia. 2004;42(2):133-141.

17. Baron-Cohen S, Ring H, Moriarty J, Schmitz B, Costa D, Ell P. Recognition of mental state terms. Clinical findings in children with autism and a functional neuroimaging study of normal adults. Br J Psychiatry. 1994;165(5):640-649.

18. Premack D, Woodruff G. Does the chimpanzee have a theory of mind? Behav Brain Sci. 1978;1(4):515-526.

19. Milders M, Fuchs S, Crawford JR. Neuropsychological impairments and changes in emotional and social behavior following severe traumatic brain injury. J Clin Exp Neuropsychol. 2003;25(2):157-172.

20. Havet-Thomassin V, Allain P, Etcharry-Bouyx F, Le Gall D. What about theory of mind after severe brain injury? Brain Inj. 2006;20(1):83-91.

21. Geraci A, Surian L, Ferraro M, Cantagallo A. Theory of mind in patients with ventromedial or dorsolateral prefrontal lesions following traumatic brain injury. Brain Inj. 2010;24(7-8):978-987.

22. Bivona U, Riccio A, Ciurli P, et al. Low self-awareness of individuals with severe traumatic brain injury can lead to reduced ability to take another person's perspective. J Head Trauma Rehabil. 2014;29(2):157-171.

23. Abell F, Happé FG, Frith U. Do triangles play tricks? Attribution of mental states to animated shapes in normal and abnormal development. Cogn Dev. 2000;15(1):1-16. 
24. Das P, Lagopoulos J, Coulston CM, Henderson AF, Malhi GS. Mentalizing impairment in schizophrenia: a functional MRI study. Schizophr Res. 2011;134(2-3):158-164.

25. McDonald S. Impairments in social cognition following severe traumatic brain injury. J Int Neuropsychol Soc. 2013;19(3):231-246.

26. Bibby H, McDonald S. Theory of mind after traumatic brain injury. Neuropsychologia. 2005;43(1):99-114.

27. Newsome MR, Scheibel RS, Chu Z, et al. The relationship of resting cerebral blood flow and brain activation during a social cognition task in adolescents with chronic moderate to severe traumatic brain injury: a preliminary investigation. Int J Dev Neurosci. 2012;30(3):255-256.

28. Arlinghaus KA, Shoaib AM, Trevor RP. Neuropsychiatric assessment. In: Silver JM, McAllister TW, Yudofsky SC, editors. Textbook of Traumatic Brain Injury. Washington, DC, USA: American Psychiatric Publishing; 2005.

29. Russell W, Smith A. Post-traumatic amnesia in closed head injury. Arch Neurol. 1961;5(1):4-17.

30. World Health Organisation. ICD-10 Classifications of Mental and Behavioural Disorder: Clinical Descriptions and Diagnostic Guidelines. Geneva: World Health Organisation; 1992.

31. Wilson BA. In: Wilson BA, Alderman N, Burgess PW, Emslie H, Evans J, editors. Behavioural Assessment of the Dysexecutive Syndrome. Bury St Edmunds, UK: Thames Valley Test Company; 1997.

32. Matsumoto D, Ekman P. Japanese and Caucasian Facial Expressions of Emotion. San Francisco, CA, USA; Human Interaction Laboratory, University of California; 1988.

33. Sato W, Kubota Y, Okada T, Murai T, Yoshikawa S, Sengoku A. Seeing happy emotion in fearful and angry faces: qualitative analysis of facial expression recognition in a bilateral amygdala-damaged patient. Cortex. 2002;38(5):727-742.

34. Stone VE, Baron-Cohen S, Knight RT. Frontal lobe contributions to theory of mind. J Cogn Neurosci. 1998;10(5):640-656.

35. Baron-Cohen S, Wheelwright S, Hill J, Raste Y, Plumb I. The 'Reading the Mind in the Eyes' test revised version: a study with normal adults, and adults with Asperger syndrome or high functioning autism. J Child Psychol Psychiatry. 2001;42(2):241-251.

36. Whiteneck GG. Outcome analysis in spinal cord injury rehabilitation. In: Fuhrer MI, editor. Rehabilitation Outcomes: Analysis and Measurement. Baltimore, MD, USA: P. H. Brookes; 1987.
37. Kumamoto K, Iwatani T, Tobimatsu Y, Kumano H, Sonoda K, Tozato F. [Development of the Japanese version of the CHART]. Sougou Rehabilitation. 2002;30(3):249-256. Japanese.

38. Whiteneck GG, Charlifue SW, Gerhart KA, Overholser JD, Richardson GN. Quantifying handicap: a new measure of long term rehabilitation outcomes. Arch Phys Med Rehabil. 1992;73(6):519-526.

39. Kubota Y, Quérel C, Pelion F, et al. Facial affect recognition in prelingually deaf people with schizophrenia. Schizophr Res. 2003;61(2-3): 265-270.

40. Hirao K, Miyata J, Fujiwara H, et al. Theory of mind and frontal lobe pathology in schizophrenia: a voxel-based morphometry study. Schizophr Res. 2008;105(1-3):165-174.

41. Koelkebeck K, Hirao K, Kawada R, et al. Impact of gray matter reductions on theory of mind abilities in patients with schizophrenia. Soc Neurosci. 2013;8(6):631-639.

42. Mellick D, Walker N, Brooks CA. Incorporating the cognitive independence domain into CHART. J Rehabil Outcomes Meas. 1999; 3(3):12-21.

43. Hall KM, Bushnik T, Lakisic KB, Wright J, Cantagallo A. Assessing traumatic brain injury outcome measures for long-term follow-up of community-based individuals. Arch Phys Med Rehabil. 2001;82(3): 367-374.

44. Kinnunen KM, Greenwood R, Powell JH, et al. White matter damage and cognitive impairment after traumatic brain injury. Brain. 2011; 34(2):449-463.

45. Levine B, Kovacevic N, Nica EI, Schwartz ML, Gao F, Black SE. Quantified MRI and cognition in TBI with diffuse and focal damage. Neuroimage Clin. 2013;2:534-541.

46. Roca M, Torralva T, Gleichgerrcht E, et al. The role of area 10 (BA10) in human multitasking and in social cognition: a lesion study. Neuropsychologia. 2011;49(13):3525-3531.

47. Brothers L. The social brain: a project for integrating primate behavior and neurophysiology in a new domain. Concepts in Neuroscience. 1990; $1: 27-51$.

48. Frith CD. The social brain? Philos Trans R Soc Lond B Biol Sci. 2007; 362(1480):671-678.

49. Ownsworth T, Clare L. The association between awareness deficits and rehabilitation outcome following acquired brain injury. Clin Psychol Rev. 2006;26(6):783-795
Neuropsychiatric Disease and Treatment

\section{Publish your work in this journal}

Neuropsychiatric Disease and Treatment is an international, peerreviewed journal of clinical therapeutics and pharmacology focusing on concise rapid reporting of clinical or pre-clinical studies on a range of neuropsychiatric and neurological disorders. This journal is indexed on PubMed Central, the 'PsycINFO' database and CAS,

\section{Dovepress}

and is the official journal of The International Neuropsychiatric Association (INA). The manuscript management system is completely online and includes a very quick and fair peer-review system, which is all easy to use. Visit http://www.dovepress.com/testimonials.php to read real quotes from published authors. 